\title{
Engineering Size and Structure of Particles in Novel Modified-Release Delivery Systems
}

\author{
Qianqian Dong ${ }^{1,2, a}$, Xiao Zheng ${ }^{1, a}$, Miaomiao Zhou ${ }^{1}$, Fei Wu ${ }^{2}$, Yanlong Hong ${ }^{2}$, Xiao Lin ${ }^{1}$, Lan Shen ${ }^{2}$ \\ ${ }^{1}$ College of Chinese Materia Medica, Shanghai University of Traditional Chinese Medicine, Shanghai 201203, PR \\ China; ${ }^{2}$ Engineering Research Center of Modern Preparation Technology of TCM of Ministry of Education, Shanghai \\ University of Traditional Chinese Medicine, Shanghai 201203, PR China
}

Received, January 21, 2019; Revised, April 9, 2019; Accepted, April 11, 2019; Published, April 11, 2019.

\begin{abstract}
Particle engineering has become a hot topic in the field of modified-release delivery systems during last decades. It has a wide range of pharmaceutical applications and is a bridge linking between drugs and drug delivery systems. Particles are an important part of many dosage forms and viewed as a carrier of drugs. Their size, shape, crystalline form, and structure directly affect the stability and releasing pattern of drugs. Engineering size or modifying particles by forming porous, core-shell, or skeleton structures can realize the development and utilization of functionally modified release systems (including fast-release systems, sustained-release systems, and targeted-release systems). However, there are certain problems in the practical application, such as bitter taste and coating damage. Combining with some polymer or lipid materials to form core-shell or embedded structures is considered as the key to taste masking. And, using cushioning agents is proven to be effective in preserving the integrity of the functional coating film of multiparticulates during tableting. To sum up, this review, from a particle engineering point, expounds the influence of different factors on the functionality of particles and offers some useful comments and suggestions for industry personnel.
\end{abstract}

\section{INTRODUCTION}

Multiple-unit microparticles are considered as the cornerstone in the modified release delivery system. Although they exist in various forms in the manufacturing processes, the prototypes of them are all particles. Based on the principle of particle engineering, particles treated with different technologies to form special structures could achieve various functional outcomes.

Particle engineering, a young discipline, combines elements of many others, including chemistry, pharmaceutics, interface and colloid science, mass and heat transfer, aerosol and powder science, solid state physics, etc (1). It can guide a rational design of microparticles with specific structures by providing a theoretical framework (1). Microparticles can perfect their characteristics via particle engineering to improve derived functional properties. Fundamental characteristics of materials directly determine their functional properties (2). Therefore, both of modifying particles with single component and co-processing for production of composite particles will be hopeful to improve or change the performance of pharmaceutical formulations, resulting in ultimately patient benefits. Porous structure, core-shell structure, or skeleton structure can realize the development and utilization of functionally modified release systems (i.e., fast-release systems, sustained-release systems, and targeted-release systems). On the other hand, the addition of some special materials using different processing technologies such as coating, hot-melting extrusion, and chemical modification is usually the key to the formation of specific particle structures.

However, some hidden problems that restrict their use are found in the practical application, such as bitter taste and coating damage. Combining with some polymer materials to form a core-shell structure or embedded structure is considered to be the key to taste masking. For the coating damage under tableting, micronized additives and some particularly deformable materials can act as the role of cushioning agents. All in all, particle engineering plays an increasingly vital role in the modification of materials.

Corresponding Author: Xiao Lin. College of Chinese Materia Medica, Shanghai University of TCM, Shanghai 201203, PR China; Email: duotang@163.com (X. Lin) \& Lan Shen. Engineering Research Center of Modern Preparation Technology of TCM of Ministry of Education, Shanghai University of TCM, Shanghai 201203, PR China; Email: shutcms1@163.com (L. Shen). ${ }^{\text {aThese two authors }}$ contributed equally to this work. 
In this review, novel modified release delivery systems: fast-release systems, sustained-release systems, and targeted-release systems are introduced and the principles of particle engineering in the particle formation process are described. The novel technologies and processing methods in the last few years along with some problems and solutions concerned in application and development processes are also summarized. The overall aim is to inform the readers of some potential functionality that can be accomplished through the various material modification via particle engineering, thereby offering some hints for further in-depth researches.

\section{The application of particle engineering in modified release systems}

The particle engineering is a young discipline but widely applied in various modified drug delivery systems. Structured particles produced based on the principle of particle engineering often exhibit improved functional outcomes. Modification of single-component or composite particles creates special structures (e.g., porous structure, core-shell structure, and skeleton structure) that are closely related to the way of drug release, either the release rate (i.e., fast release or sustained release) or the release region (i.e., targeted release). Next, the information about each case, mainly the preparation technology and function mechanism, is summarized and discussed in detail.

\section{The application in the fast-release systems}

The orally disintegrating tablet (ODT) is a representative of the fast-release systems (Table 1). Particles forming a porous structure via special treatment can not only improve the formability of tablets, but also enhance drug bioavailability by increasing drug dissolution velocity and decreasing disintegration time. For ODTs, an increasing of porosity can accelerate dissolution media into tablets and, thus, is regarded as a highly effective direction for development. However, overhigh porosity can also bring about poor mechanical strength of tablets as well. For this reason, the novel methods that helped to maintain high porosity while met required mechanical strength of tablets were developed. On the other hand, the modification of drug particles via integrated crystal and particle engineering was exploited to enhance tablet formability.

In addition to reducing the disintegration time, increasing the solubility is another effective method to improve drug bioavailability. For water insoluble drugs, accelerating tablet disintegration may not effectively improve their bioavailability because they're just scattered but not dissolved. Cyclodextrin inclusion technique can solve this problem very well by the formation of drug-cyclodextrin complex with improved solubility due to the hydrophilic outer surface of cyclodextrin.

\section{The improvement of ODT's bioavailability}

Dissolution rate and disintegration time are two main characteristics of dosage forms that directly affect the bioavailability of drugs. In order to meet the requirements of drug release, some methods are put forward. Based on the particle engineering principle, increasing specific surface area by increasing porosity can significantly improve the dissolution rate and disintegration time, and, in turn, the bioavailability of drugs especially poorly insoluble ones.

To ensure ideal disintegration performance of ODTs, the tablet porosity that directly affects the rate of water through the tablet matrix is claimed. It is well known that high porosity facilitates better water ingress and tablet swelling than low porosity (3). The spray drying technique is an efficient method for preparation of porous structures. And, to achieve a higher porosity, the principle of producing gas during spray drying could be used. For example, previous studies have revealed that ammonium bicarbonate $\left(\mathrm{NH}_{4} \mathrm{HCO}_{3}\right)$ can sublime and evolve into $\mathrm{H}_{2} \mathrm{O}, \mathrm{NH}_{3}$ and $\mathrm{CO}_{2}$ above $50^{\circ} \mathrm{C}(4,5)$. Therefore, $\mathrm{NH}_{4} \mathrm{HCO}_{3}$ is used as a pore former in spray drying to leave voids in forming particles (6). On the other hand, the principle of templating could also be used to achieve the same purpose. For example, porous lactose particles were prepared by spray drying a solution containing lactose, whey protein isolate, and ethanol-soluble citric acid as a templating agent followed by the removal of citric acid by ethanol treatment (7). The achieved structure was a lactose network full of pores, which created a high specific surface area while preserving the strong structural stability of a highly crystalline powder. As a whole, both of the methods ensured rapid tablet disintegration on account of high porosity while kept high mechanical strength of tablets due to large surface areas. 
Table 1. Application of particle engineering in fast-release systems

\begin{tabular}{|c|c|c|c|c|c|}
\hline Type & Product & Processing & Structure & Properties & Reference \\
\hline \multirow{35}{*}{$\begin{array}{l}\text { Improving } \\
\text { bioavailability }\end{array}$} & $\alpha$-lactose & Spray drying & Porous & Special $\quad$ surface $\quad$ area $\uparrow$ & $(7)$ \\
\hline & monohydrate/citr & & structure & 95.33-fold, $\quad$ size $\downarrow$ & \\
\hline & ic acid & & & 0.69 -fold & \\
\hline & monohydrate & & & & \\
\hline & /whey protein & & & & \\
\hline & isolate & & & & \\
\hline &, $50 / 1 / 10$ & & & & \\
\hline & Mannitol/ammon & Spray drying & Porous & Porosity $\uparrow 1.65$-fold, Size $\downarrow$ & (6) \\
\hline & ium bicarbonate, & & structure & $0.49 \sim 0.62$-fold & \\
\hline & $2 / 1$ & & & Disintegration time $\downarrow 0.50$ & \\
\hline & & & & $\sim$ 0.77-fold, hardness $\uparrow$ & \\
\hline & & & & 1.5 -fold (under $110^{\circ} \mathrm{C}$ ), & \\
\hline & & & & 0.30 -fold (under $150^{\circ} \mathrm{C}$ ) & \\
\hline & PPZ/HP- $\beta-C D$, & Evaporation & Poikilitic & Dissolution $\quad$ rate $\uparrow$ & $(8)$ \\
\hline & $1 / 1$ & method & texture & 3.76-fold, wetting time $\downarrow$ & \\
\hline & & & & $\begin{array}{l}0.56 \text {-fold, disintegration } \\
\text { time } \downarrow 0.70 \text {-fold }\end{array}$ & \\
\hline & CLZ/HP- $\beta-C D$, & Evaporation & Poikilitic & Dissolution & (9) \\
\hline & $1 / 1$ & method & texture & 75.00-fold & \\
\hline & $\mathrm{CLZ} / \beta-\mathrm{CD}, 1 / 2$ & Spray drying & Poikilitic & Contact angle $\downarrow 0.63$-fold, & $(10)$ \\
\hline & & & texture & dissolution $\quad$ rate $\uparrow$ & \\
\hline & & & & 7.64-fold, disintegration & \\
\hline & & & & time $\downarrow 0.12$-fold & \\
\hline & $\mathrm{IB} / \beta-\mathrm{CD}, 1 / 1$ & Spray drying & Poikilitic & Dissolution rate $(\mathrm{IB}) \uparrow$ & (11) \\
\hline & $\mathrm{IN} / \beta-\mathrm{CD}, 1 / 1$ & Freeze drying & texture & 3.22-fold (SD)/3.20-fold & \\
\hline & & & & $(\mathrm{FD})$ & \\
\hline & & & & Dissolution rate $(\mathrm{IN}) \uparrow$ & \\
\hline & & & & 3.54-fold $\quad(\mathrm{SD}) / 2.96$-fold & \\
\hline & & & & $(\mathrm{FD})$ & \\
\hline & $\mathrm{MEL} / \beta-\mathrm{CD}, 1 / 1$ & Physical mixing/ & Poikilitic & Dissolution $\quad$ rate $\uparrow$ & (13) \\
\hline & & Kneading method/ & texture & 0.67-fold (PM/MEL) & \\
\hline & & Spray drying & & & \\
\hline & $\mathrm{LMG} / \beta-\mathrm{CD}, 1 / 1$ & Kneading method & Poikilitic & Dissolution & (14) \\
\hline & & & texture & 10.98-fold & \\
\hline & $\mathrm{MEL} / \beta-\mathrm{CD}$ & Kneading method & Poikilitic & Dissolution & $(15)$ \\
\hline & & & texture & 1.50 -fold & \\
\hline \multirow{7}{*}{$\begin{array}{l}\text { Improving } \\
\text { formability }\end{array}$} & Erythritol/porous & Spray drying & Porous & $\mathrm{TS} \uparrow 1.77$-fold & $(16)$ \\
\hline & $\begin{array}{l}\text { silica, } 0.5 / 1,1 / 1 \text {, } \\
2 / 1 \text { or } 3 / 1\end{array}$ & & structure & & \\
\hline & Mannitol/tapioca & Co-fusion/ & - & $\mathrm{TS} \uparrow \mathrm{GTM} / \mathrm{TPS}: \quad 0.16 \sim$ & $(18)$ \\
\hline & starch, $1 / 1$ & Co-grinding & & 0.31 -fold (IG), $0.41 \sim$ & \\
\hline & & & & 1.36-fold $\quad(E G)$ & \\
\hline & & & & FTM/TPS: $\sim$ 0.14-fold & \\
\hline & & & & $(\mathrm{IG}), \quad 0.49 \sim 1.24$-fold & \\
\hline
\end{tabular}




\begin{tabular}{|c|c|c|c|}
\hline & & & $(\mathrm{EG})$ \\
\hline & & & Friability $\downarrow \quad$ GTM/TPS: \\
\hline & & & $3.02 \sim$ 5.81-fold $(\mathrm{IG})$ \\
\hline & & & $2.42 \sim 13.84$-fold $(\mathrm{EG})$ \\
\hline & & & FTM/TPS: $\sim 0.75$-fold \\
\hline & & & (IG), $1.41 \sim 11.16$-fold \\
\hline & & & $(E G)$ \\
\hline MET/Acs, & Anion & Solitary & $\mathrm{TS} \uparrow$ \\
\hline $1.66 / 2.01$ & exchange reaction & crystal & Dissolution $\quad \operatorname{rate} \uparrow$ \\
\hline & & & 0.63-fold ( for MET-HCl) \\
\hline DPH/Acs, & Synthesis & Solitary & $\mathrm{TS} \uparrow \quad 3.40$-fold $\quad$ (for \\
\hline $29.18 / 20.2$ & & crystal & DPH-HCl ), \\
\hline & & & Disintegration \\
\hline & & & 8.80-fold (for DPH-HCl) \\
\hline
\end{tabular}

PPZ, perphenazine; HP- $\beta$-CD, hydroxypropyl- $\beta$-cyclodextrin; CLZ, clozapine; $\beta$-CD, beta cyclodextrin; IB, ibuprofen; IN, indomethacin; MEL, meloxicam; LMG, lamotrigine; MNT, mannitol; TPS, tapioca starch; FTM, coprocessed product by co-fusion; GTM, coprocessed product by co-grinding; MET, metformin; Acs, acesulfame; $\mathrm{DPH}$, diphenhydramine; PM, physical mixture; SD, spray drying; FD, freeze drying; IG, intragranular; EG, extragranular; TS, tensile strength.

In fact, it's not a rational proposal for water-insoluble drugs to improve bioavailability just through increasing disintegration rate, because they're just scattered but not dissolved. With deeper research, the cyclodextrin complexation technique was employed to improve the solubility and oral bioavailability of poorly water-soluble drugs loaded in ODTs. The inclusion complexes were often prepared by an evaporation method or a spray-drying technique (8-10). Thereinto, the water-insoluble drugs were wrapped in the center of cyclodextrin molecules which have hydrophobic internal cavities and hydrophilic outer surfaces. Owing to these properties, the final formation of inclusion complexes with particular structures could significantly increase the dissolution and bioavailability of lipophilic drugs (9). Finally, all the results indicated that the developed ODTs with low disintegration time by direct compaction met the basic properties of tablets, thus providing a promising way for fast drug delivery (8-10). In addition, grinding, kneading, co-precipitation, freeze drying, and microwave radiation were also used to prepare cyclodextrin inclusion (11-14). For example, in a study, two methods were considered: (i) kneading of a binary mixture and (ii) inclusion of either ibuprofen or indomethacin in aqueous solutions of beta-cyclodextrin followed by removing water by air stream, freeze-drying, or spray-drying. One of the findings was that neither the methods of complexation nor the processes of drying did significantly affect the final entrapment efficiency (11). Although increasing mixing time and the amount of solvent could increase drug loading and release for the kneading method, removing the solvent was a potential problem (15). What's more, the researchers also compared three methods (kneading, co-precipitation, and spray drying) for the preparation of meloxicam $/ \beta$-cyclodextrin complexes. Spray drying, by contrast, significantly enhanced the dissolution rate and drug release due to formation of an amorphous complex $(12,13)$.

\section{The improvement of ODT's formability}

High porosity can promote tablet disintegration; however, overhigh porosity may also bring poor tablet strength. In order to produce mechanically hard ODTs, particle engineering is actively used to prepare multifunctional excipients for the achievement of reasonable values of tablet hardness and friability (16). Thereinto, spray drying is one of the most popular engineering technologies for preparation of composite particles used in ODTs, which often have high porosity and excellent compaction performance. For example, composite particles consisting of erythritol and porous silica were prepared by 
spray drying and then compacted into ODTs by direct tableting. The results showed that crystalline erythritol was embedded in silica pores and an erythritol/porous silica ratio of $2: 1$ improved the compactibility of erythritol to a large extent (17). In another study, novel coprocessed excipients as disintegrant were produced from tapioca starch and mannitol by two methods, i.e., co-fusion and co-grinding. The results revealed that such composite disintegrants significantly enhanced the mechanical properties of tablets as shown by high tensile strength and low friability (18).

In addition to improving the properties of excipients, the modification of drug particles is another acceptable solution. For example, the salt formation with a sweetener was regarded as a breakthrough for bitter drugs to develop ODTs by direct compaction (19). The modification of the crystal structure of drugs via integrated crystal and particle engineering successfully improved drug properties such as solubility and mechanical strength. Higher plasticity of the drug-sweetener salt ensured larger bonding area than parent crystals, hence resulting in stronger tablets. In this study, the salt of metformin with acesulfame (Acs) was prepared by an anion exchange reaction. The nanoindentation and energy framework analysis revealed that the sweet salt showed superior properties (including tabletability and taste) than the commercially available hydrochloride salt, which benefited from its special crystal structure. And this approach also made possible the ODTs containing high drug loading rate ( 60\%) (19). Similarly, the salt of diphenhydramine with Acs remarkably improved important pharmaceutical properties of the drug as well. These ODTs exhibited higher mechanical strength and lower friability due to reduction in elastic modulus (20).

\section{The application in sustained-release systems} Particle engineering not only applies in modification of single-component particles or composite particles for ODTs, but also assists in achieving wider applications in sustained-release formulations (Table 2, Figure 1). In general, most of these preparations are done with polymeric materials by forming a core-shell structure to achieve special function applications via coating. The coating methods used mainly include conventional hot-melt coating with pan, fluidized bed coating, and dry coating, which have their own typical characteristics. The formation of coating film reduces the speed of water into the core and further exerts a certain effect on the sustained release. Next, these particularly functional preparations together with their manufacturing process and application are introduced in detail.
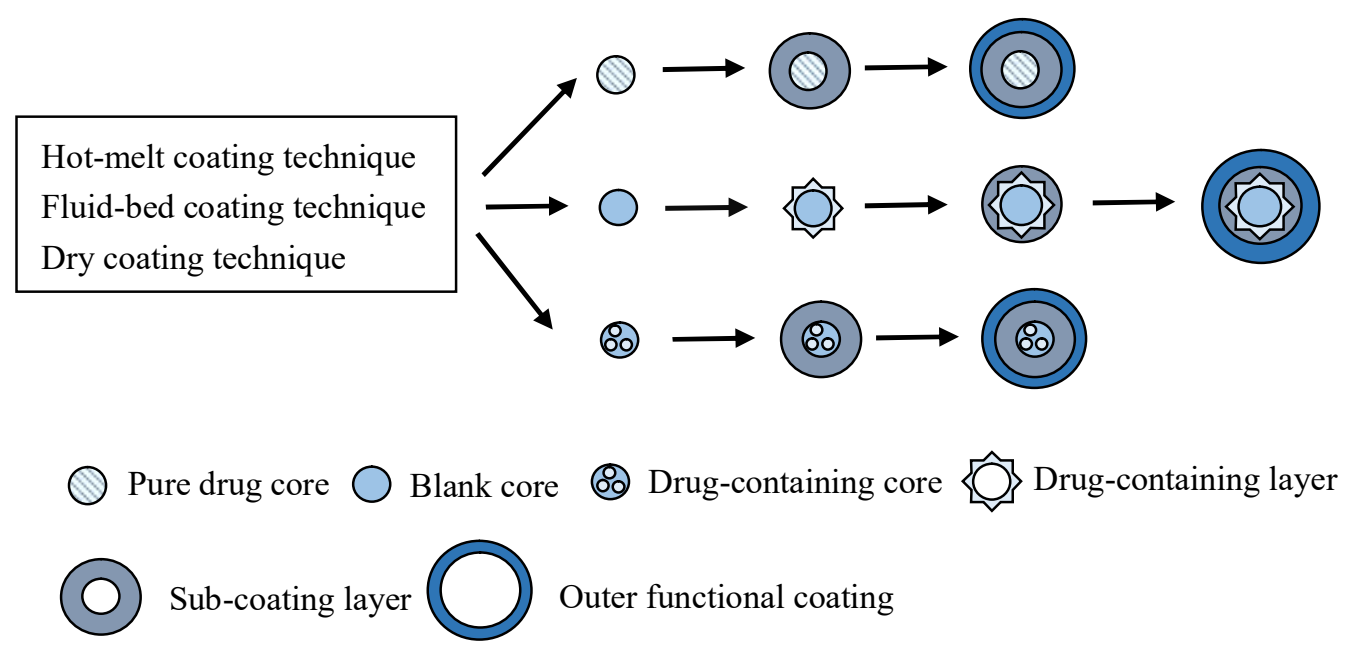

Figure 1. Applied forms of particle engineering in sustained-release systems 
Table 2. Application of particle engineering in sustained-release systems

\begin{tabular}{|c|c|c|c|c|}
\hline Product & Process & Structure & Properties & Reference \\
\hline Eudragit VR EPO/EC/MT, 7/63/30 & $\begin{array}{l}\text { Hot-melt coating } \\
\text { method }\end{array}$ & $\begin{array}{l}\text { Core-shell } \\
\text { structure }\end{array}$ & $\begin{array}{l}\mathrm{T}_{\max } \uparrow \quad 7.00 \text {-fold, } \mathrm{C}_{\max } \downarrow \\
0.99 \text {-fold, } \quad \mathrm{AUC}_{0-12} \uparrow \\
0.32 \text {-fold }\end{array}$ & $(23)$ \\
\hline $\begin{array}{l}\text { SGL/Compritol } 888 \text { ATO/HPMC K15, } \\
1 / 0.25 / 0.5\end{array}$ & Hot-melt method & $\begin{array}{l}\text { Skeleton } \\
\text { structure }\end{array}$ & $\begin{array}{l}\text { AUC } \uparrow \quad 1.7 \text {-fold, } \mathrm{C}_{\max } \downarrow \\
0.91 \text {-fold, } \mathrm{T}_{\max } \uparrow 17.86 \%, \\
\mathrm{~K}_{\mathrm{e}} \downarrow 38.70 \%\end{array}$ & $(24)$ \\
\hline $\begin{array}{l}\text { FF/sugarsyrup/CG/EC } \\
\text { / } \alpha \text {-tocopherol, 200/40/18/6/1 }\end{array}$ & $\begin{array}{l}\text { Hot-melt coating } \\
\text { method }\end{array}$ & $\begin{array}{l}\text { Core-shell } \\
\text { structure }\end{array}$ & Release rate $\downarrow$ & $(25)$ \\
\hline $\begin{array}{l}\text { Paracetamol/lactose/PVPK-30 } \\
\text { /glyceryl behanate, }(80 / 17 / 3) / 9\end{array}$ & $\begin{array}{l}\text { Hot-melt coating } \\
\text { method }\end{array}$ & $\begin{array}{l}\text { Core-shell } \\
\text { structure }\end{array}$ & $\mathrm{C}_{\max } \downarrow, \quad \mathrm{AUC} \uparrow$ & $(26)$ \\
\hline $\begin{array}{ll}(\mathrm{PH} / \mathrm{MCC} / \text { octadecanol, } & 50 / 25 / 25) / \\
\text { stearic acid }(10 \% \text { level }) / & \text { Eudragit }{ }^{\circledR}\end{array}$ & $\begin{array}{l}\text { Hot-melt coating } \\
\text { method }\end{array}$ & $\begin{array}{l}\text { Core-shell } \\
\text { structure }\end{array}$ & Release rate $\downarrow$ & $(27)$ \\
\hline NE 30D (5\% level) & $\begin{array}{l}\text { Fluidized bed } \\
\text { top-spray coating } \\
\text { method }\end{array}$ & & & \\
\hline $\mathrm{PA} / \mathrm{EC} 100 \mathrm{cp}, 1 / 6$ & $\begin{array}{l}\text { Extrusion/ } \\
\text { spheronization } \\
\text { technique } \\
\text { Fluid-bed coating } \\
\text { method }\end{array}$ & $\begin{array}{l}\text { Core-shell } \\
\text { structure }\end{array}$ & $\begin{array}{l}\text { Dissolution } \quad \text { rate } \downarrow \\
119 \text {-fold } \\
10 \mathrm{~min} / 100 \% \\
12 \mathrm{~h} / 60 \%\end{array}$ & $(28)$ \\
\hline $\begin{array}{l}\text { DIP/MCC/mannitol/EC/PVPk30/ } \\
\text { HPMC/ Eudragit@ NE 30D }\end{array}$ & $\begin{array}{l}\text { Extrusion/ } \\
\text { spheronization } \\
\text { technique } \\
\text { Fluid-bed bottom } \\
\text { coating method }\end{array}$ & $\begin{array}{l}\text { Core-shell } \\
\text { structure }\end{array}$ & $\begin{array}{lr}\mathrm{AUC}_{0-\mathrm{t}} \uparrow & 0.68 \text {-fold, } \\
\mathrm{AUC}_{0-\infty} \uparrow & 0.93 \text {-fold, } \mathrm{t}_{1 / 2} \uparrow \\
0.87 \text {-fold, } & \mathrm{T}_{\max } \uparrow \\
0.92 \text {-fold, } & \mathrm{C}_{\max } \uparrow \\
0.35 \text {-fold } & \end{array}$ & $(29)$ \\
\hline $\begin{array}{l}\text { DM/MCC/lactose monohydrate/ } \\
\text { DCPD/talc/PVP } \\
\text { K30,5.1/150/74.4/60/6/4.5 } \\
\text { Eudragit@ RS PO/PEG } \quad 6000 / \text { talc, } \\
80 / 8 / 26.7\end{array}$ & $\begin{array}{l}\text { Extrusion/ } \\
\text { spheronization } \\
\text { technique } \\
\text { Fluid-bed bottom } \\
\text { coating method }\end{array}$ & $\begin{array}{l}\text { Core-shell } \\
\text { structure }\end{array}$ & $\begin{array}{l}\text { Dissolution rate } \downarrow \\
\text { Zero-order } \mathrm{K} \downarrow 3.59 \text {-fold }\end{array}$ & $(30)$ \\
\hline 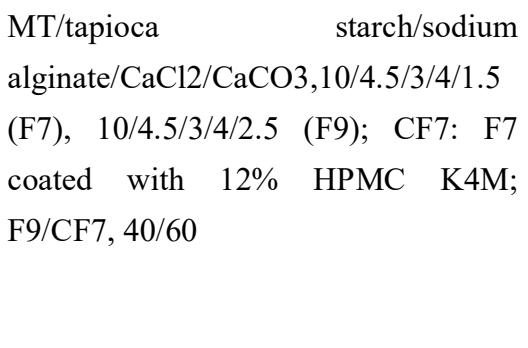 & $\begin{array}{l}\text { Ionotropic gelation } \\
\text { method } \\
\text { Fluid-bed bottom } \\
\text { coating method }\end{array}$ & $\begin{array}{l}\text { Core-shell } \\
\text { structure }\end{array}$ & $\begin{array}{l}\mathrm{C}_{\max } \downarrow \quad 1.27 \text {-fold, } \mathrm{T}_{\max } \uparrow \\
9.03 \text {-fold } \\
\text { AUC }_{(0-960 \text { min })} \uparrow 0.87 \text {-fold, } \\
\mathrm{t}_{1 / 2} \uparrow \quad 0.48 \text {-fold, } \quad \text { MRT } \uparrow \\
\text { 1.40-fold, } \\
\text { Bioavailability } \uparrow \\
0.69 \text {-fold }\end{array}$ & $(32)$ \\
\hline
\end{tabular}




\begin{tabular}{|c|c|c|c|c|}
\hline \multirow[t]{2}{*}{$\begin{array}{l}\mathrm{TS} / \mathrm{SC} / \mathrm{MCC}, 1 / 3 / 16 \\
\text { Eudragit }{ }^{\circledR} \text { RS30D/RL30D dispersion } \\
(9: 1, \mathrm{w} / \mathrm{w})\end{array}$} & $\begin{array}{l}\text { Extrusion/ } \\
\text { spheronization } \\
\text { technique }\end{array}$ & $\begin{array}{l}\text { Core-shell } \\
\text { structure }\end{array}$ & $\begin{array}{l}\mathrm{t}_{1 / 2} \uparrow \quad 1.53 \text {-fold, } \quad \mathrm{T}_{\max } \uparrow \\
\text { 3.34-fold, } \\
\mathrm{C}_{\max } \downarrow \quad 0.70 \text {-fold, } \\
\mathrm{MRT} \uparrow\end{array}$ & (33) \\
\hline & $\begin{array}{l}\text { Fluid-bed bottom } \\
\text { coating method }\end{array}$ & & $\begin{array}{l}\text { 1.93-fold, } \quad \mathrm{AUC}_{0-24 \uparrow} \uparrow \\
\text { 0.97-fold, }\end{array}$ & \\
\hline Acetaminophen/CW/talc, 30/10/4 & Dry coating & $\begin{array}{l}\text { Core-shell } \\
\text { structure }\end{array}$ & $\begin{array}{l}\text { Release rate } \downarrow \text { (Two-step } \\
\text { addition of } \mathrm{CW}< \\
\text { single-step addition of } \\
\mathrm{CW})\end{array}$ & (36) \\
\hline TPL/Eudragit ${ }^{\circledR}$ RL30D, 8/2 & Dry coating & $\begin{array}{l}\text { Core-shell } \\
\text { structure }\end{array}$ & $\begin{array}{l}\text { Dissolution } \quad \text { rate } \downarrow \sim \\
11.00 \text {-fold }\end{array}$ & (37) \\
\hline $\begin{array}{l}\mathrm{CS} / \mathrm{TP} / \mathrm{PEG} \quad 20,000 / \mathrm{HCO} / \mathrm{HRSO} \text {, } \\
7.28 / 1.44 / 2.40 / 2.82 / 4.21\end{array}$ & Dry coating & $\begin{array}{l}\text { Core-shell } \\
\text { structure }\end{array}$ & $\begin{array}{l}\text { Dissolution rate } \downarrow \sim \\
239.00 \text {-fold }\end{array}$ & (38) \\
\hline $\begin{array}{l}\text { EC, ethylcellulose; MT, metoprolol t } \\
\text { microcrystalline cellulose; PH, pseud } \\
\text { doxazosin mesylate; DCPD, dibasic ca } \\
\text { TS, tanshinol; SC, sodium caprate; C } \\
\text { polyethylene glycol; HCO, hydrogena } \\
\text { parameters including maximum peak } \\
\text { concentration; } \mathrm{t}_{1 / 2} \text {, half life; AUC, area }\end{array}$ & $\begin{array}{l}\text { itrate; SGL, sarpogre } \\
\text { ephedrine hydrochlor } \\
\text { cium phosphate dihyd } \\
\text { W, carnauba wax; TP } \\
\text { ted castor oil; HRSO } \\
\text { concentration of th } \\
\text { Inder the curve; MRT, }\end{array}$ & $\begin{array}{l}\text { late } \mathrm{HCl} ; \mathrm{F} \\
\text { ide; PA, pr } \\
\text { rate; PVP, p } \\
\text { L, theophyll } \\
\text { hydrogenat }\end{array}$ & $\begin{array}{l}\text { rous fumarate; CG, cow } \\
\text { echuic acid; DIP, dipyridi } \\
\text { ylpyrrolidone; MT, metopr } \\
\text { CS, cornstarch; TP, theoph } \\
\text { peseed oil; } \mathrm{C}_{\max } \text {, the phar } \\
\text {; } \mathrm{t}_{\max } \text {, the time to reacl } \\
\text { al time; } \mathrm{K}_{\mathrm{e}} \text {, elimination rate }\end{array}$ & $\begin{array}{l}\text { e; MCC, } \\
\text { le; DM, } \\
\text { tartrate } \\
\text { ne; PEG } \\
\text { cokinetic } \\
\text { naximum } \\
\text { nstant. }\end{array}$ \\
\hline
\end{tabular}

\section{Conventional hot-melt coating technique}

The lipid excipient is generally used in extended-release solid dosage forms because of its hydrophobic property, and it is active in the hot-melt coating process. Core particles can be coated with one or more waxy layers containing drugs or not. Generally, the harder the lipid, the slower the drug release from such coated particles. A near zero-order release can be achieved by double lipid-coated pellets (21). What's more, the addition of polymeric materials such as hydroxypropyl methylcellulose (HPMC) acts as a synergistic effect in the release process due to the formation of a gel layer.

The coating level and release modifiers are considered as two main factors that affect the drug-release behavior (22). Compritol 888 ATO is a commonly used hot-melt coating material that consists of a mixture of different esters of behenic acid with glycerol (23). A sustained-release solid dispersion based on waxy material carriers was investigated, which could sustain the drug release for up to $24 \mathrm{~h}$. Compritol 888 ATO, stearyl alcohol, and drug were treated by a hot-melt method and then the solidified melts were pulverized, followed by mixing with HPMC. It was found that the drug release rate from the sustained-release solid dispersion decreased with increasing the amount of HPMC, because it could form a gel layer when contacting with aqueous media (24). The functional polymer materials as a carrier or adjuvant in the sustained-release systems have attracted a lot of researchers. In a study, cow ghee, an important hot-melt coating agent, worked together with water-insoluble ethyl cellulose (EC) in the coating of pellets by conventional coating with pan. The prepared pellets with smooth surface morphology showed a remarkable sustained-release effect (25).

Particles modified by the hot-melt coating process could be not only directly prepared into pellets, but also compacted into tablets or filled into capsules to achieve sustained drug delivery in an optimum period. In a study, the sustained-release tablets were prepared by granules that were made of drug and particular fillers and then coated with different levels of lipid (26). The results showed that the composition of the granule that could be manipulated by changing the amount of lipid in the formulation directly affected the drug release pattern. Thereinto, the granules, containing lactose as matrix and $9 \%(\mathrm{w} / \mathrm{w})$ glyceryl behanate as coating, were regarded as the ones with the best release profile (26).

Based on the design concept of double layers 
mentioned above, a combination of hot-melt subcoating and outer polymer coating by fluidized bed was developed. Stearic acid was selected for hot-melt subcoating which was done by using a coating pan. Next, the outer polymer coating using soft and flexible Eudragit NE30D was completed in a fluidized bed coater. The subcoating acted as a barrier between the drug-containing pellets and the polymer coating layer, preventing migration of the drug during coating the polymer. Compared with coating the polymer only, subcoating with stearic acid significantly enhanced the effect of sustained release and thus reduced the degree of polymer coating needed (27).

\section{Fluid bed coating technique}

Considering the high operating temperature of the hot-melt technique and its damage to unstable drugs, the fluid-bed coating technique, a lower temperature operating method, is applied in the preparation of sustained release preparations. Coating inner cores with drug and polymer by a single-step fluidized bed bottom-spray coating technique could form a core-shell structure with special functions. Such pellets usually have a complex multilayer structure, including a drug-containing core and/or layer, a release retarding film, and other special function layer (s) from inner to outer (28).

In a study, a pellet drug delivery system was composed of (i) microcrystalline cellulose (MCC)/octadecanol mixed matrix cores produced by extrusion-spheronization and (ii) drug/EC solid dispersion coatings prepared by fluidized bed coating (28). In another experiment, pellets consisting of a matrix core, a drug-containing HPMC layer, a HPMC subcoating, and a retarding layer (Eudragit NE 30D) were also prepared by the same methodology (29). Compared with the latter, EC acted as a sustained-release dispersion carrier in the former. And, using EC instead of HPMC and Eudragit could significantly reduce the amount of coated materials for a comparable sustained drug release. In the end, both of the optimized pellets could efficiently sustain the drug release for 12 hours $(28,29)$.

In the study of sustained-release doxazosin mesylate pellets (also prepared by extrusion-spheronization followed by fluidized bed coating), it was found that (i) the drug dissolution was proportionally sustained with the increase of the content ratio of MCC to drug, (ii) Eudragit RS PO had more remarkable sustaining effect than Eudragit RL PO, and (iii) the effect was more remarkable with the increasing of the coating level (30). Besides the ratio and type of the coating polymers, other experiments demonstrated that the effect of sustained-release agents was also influenced by types of initial cores. Besides commonly used MCC, some of natural compounds such as sugar, isomalt, and tapioca starch were also used as pellet cores (31, 32). Coating non- or medicated cores with drug and polymers by fluid-bed coating is a commonly used method for the preparation of multiple-unit sustained-release dosage forms. In some cases, drug crystals could be directly used as initial cores and effectively coated to achieve extended release as well (33).

What's more, the size and solubility of inner cores might also be factors associated with the sustained release behavior. In a study, methyl blue and aspartame, sparingly and freely water-soluble materials, respectively, were used as model drugs and coated with a lipid film by fluidized bed coating (34). Thereinto, drug-loaded mannitol microparticles with the size of 500 or $300 \mu \mathrm{m}$ served as inner cores and two lipids 'hard fat and glyceryl stearate' acted as coating materials. It was found that the two coating materials led to similar burst and sustained release rates in spite of higher wettability of glyceryl stearate. And a larger inner core showed lower burst release. That was because the larger cores carried a thicker lipid layer under the same lipid to mannitol ratio. On the other hand, as expected, sparingly water-soluble methyl blue showed a lower release rate than freely soluble aspartame (34). For hydrophilic drugs, their relatively faster release rate and poor intestinal absorption are both against the preparation of sustained-release dosage forms. In a study, sodium caprate was studied as an intestinal absorption enhancer to improve oral bioavailability of such a drug (35). The inner cores, prepared with tanshinol, sodium caprate, and MCC using extrusion-spheronization, were treated with Eudragit RS30D/RL30D as coating material via fluidized bed coating. Various indicators showed that the core-shell particles formed could significantly prolong the drug release and improve its efficacy (35).

To sum up, no matter what types of inner cores and drug distribution the composite particles have, coating with polymers by fluid-bed coating is deeply embodied in the experiments mentioned above and played a key role in the links of the whole design. 


\section{Dry coating technique}

Solventless dry powder coating methods are not only simpler, safer, and easier to scale up, but also more economical and environmentally friendly than solvent-based methods (36). Moreover, dry coating can effectively avoid (i) the influence of moisture and temperature on drug stability and (ii) the incompatibility of drugs in a prescription as well.

In a study, acetaminophen (a model drug) and carnauba wax were selected as core particle and coating material, respectively. Mixing them with or without talc was achieved by a mechanofusion system. The results showed that the dissolution rate of drug decreased with an increase in talc levels up to $40 \%$ of the amount of carnauba wax. Interestingly, two-step addition of wax could lead to more effective coating and sustained drug release than single-stepping (36).

Unlike the fluidized bed coating, in a dry coating process, the shape of inner cores is often another non-ignorable factor that influences the efficiency of coating. Generally, the more rounded drug crystals are, the easier the coating process goes on. So, a two-step powder processing including core-shape modification and drying coating was developed for preparing sustained-release particles in a study (37). Spherical drug crystals with narrow size distribution were produced by a mechanical powder processor. And the more rotation speed it had, the more rounded drug crystals were achieved. Then the shape-modified drug crystals were treated with the Eudragit RL30D nanoparticle agglomerate as coating material via mechanical powder processing. The composite particles formed showed satisfactory sustained-release behaviors. Moreover, further improved coating performance was achieved with the use of porous nanoparticle agglomerates as guest particles, due to the formation of fine fragments under mechanical stress (37).

In addition, in another study, an ultrahigh-speed mixer was used to achieve coating for cores as small as $16 \mu \mathrm{m}$, and multi-layer coated single-core particles with less than $50 \mu \mathrm{m}$ in diameter were finally prepared (38). More specifically, the cornstarch core was coated with a drug reservoir layer and a controlled-release layer where PEG 20,000 worked as drug fixative, while hydrogenated castor oil and hydrogenated rapeseed oil played a role in controlling drug release. Evidence indicated that the multi-layer coated single-core particles produced could be applied in sustained-release systems (38).

\section{The application in targeted-release systems}

The colon-targeted delivery is mostly achieved by the outer enteric coating of drug-loaded multiple-unit preparations (e.g., microspheres and beads) (Table 3, Figure 2). The inner core of such preparations is commonly prepared with different ratios of drug and matrix material (s) (like chitosan, pectin, and alginate) by the emulsion dehydration method or electrospraying method, while the formation of coating film is completed with pH-sensitive polymer (s) (like Eudragit) by the solvent evaporation method, spray coating, or polyelectrolyte multilayer coating. Multiple-unit preparations have more advantages than single unit systems for colon targeting. They can help drug not only reach the colon more quickly and steadily, but also reside there much longer (39).

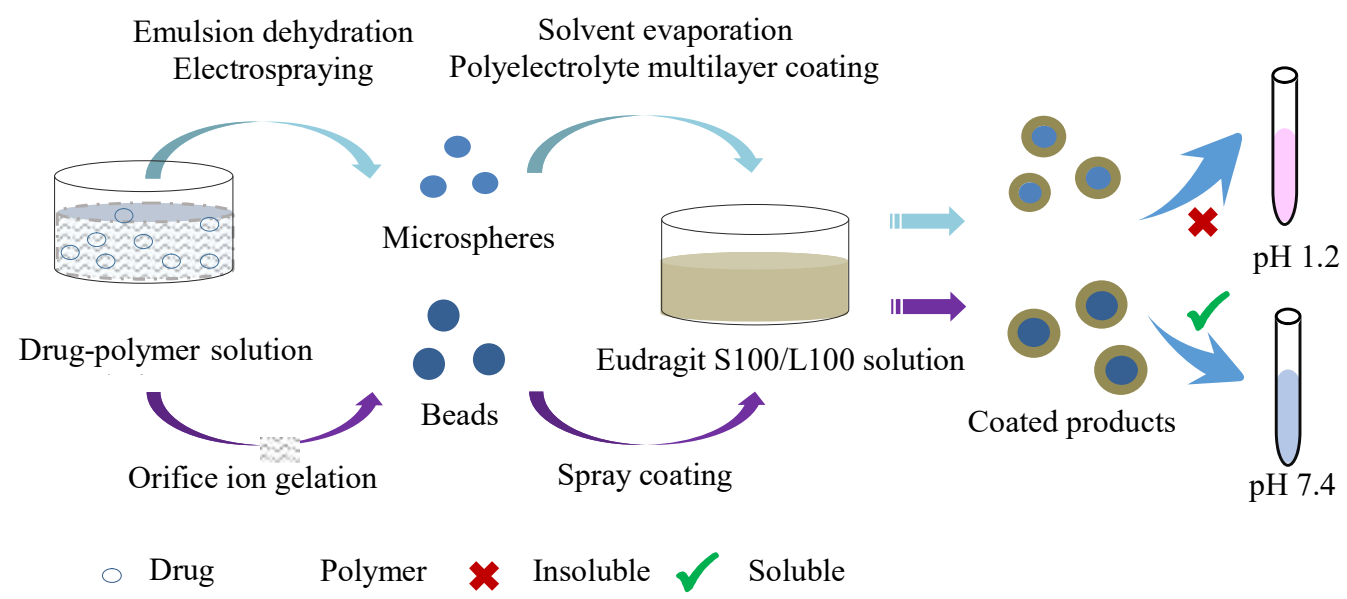

Figure 2. The application of particle engineering in targeted-release systems 
Table 3. Application of particle engineering in targeted-release systems

\begin{tabular}{|c|c|c|c|c|}
\hline Product & Process & Structure & Properties & Reference \\
\hline $\begin{array}{l}\text { Core } \quad \text { (Chitosan, } \\
\text { metronidazole)/ shell (Eudragit } \\
\mathrm{L}-100 \text { or S-100), 1:5 or } 1: 10\end{array}$ & $\begin{array}{l}\text { Emulsion method } \\
\text { Emulsion solvent } \\
\text { evaporation } \\
\text { technique }\end{array}$ & $\begin{array}{l}\text { Core-shell } \\
\text { structure }\end{array}$ & $\begin{array}{l}\text { Core: particle size, } 10.2 \mu \mathrm{m} \sim \\
15.2 \mu \mathrm{m} \\
\text { Entrapment rate, } 56.2 \% \sim 79.9 \% \\
\text { Before: } 90.8 \% \sim 99.5 \% \text { drug } \\
\text { release with } 8 \mathrm{~h} \\
\text { After: no drug release }(\mathrm{pH} 6.8), \\
50.4 \% \text { drug release }(\mathrm{pH} 7.4)\end{array}$ & (40) \\
\hline $\begin{array}{l}\text { Core (5-fluorouracil/pectin, } \\
1: 3 \text { to } 1: 6) / \text { shell (Eudragit } \\
S-100), 1: 5\end{array}$ & $\begin{array}{l}\text { Emulsion } \\
\text { dehydration } \\
\text { technique } \\
\text { Solvent } \\
\text { evaporation } \\
\text { technique }\end{array}$ & $\begin{array}{l}\text { Core-shell } \\
\text { structure }\end{array}$ & $\begin{array}{l}\text { Core: particle size, } 25 \mu \mathrm{m} \sim 32 \\
\mu \mathrm{m} \\
\text { Entrapment rate, } 64.55 \% \sim \\
74.85 \% \\
\text { Before: no drug release in colon } \\
\text { After: } 66.3 \% \text { drug release in } \\
\text { colon }(\mathrm{pH} \mathrm{7.4)}\end{array}$ & $(42)$ \\
\hline $\begin{array}{l}\text { Core (pectin, metronidazole) } \\
\text { / shell (Eudragit S-100), 1:5 or } \\
1: 10\end{array}$ & $\begin{array}{l}\text { Emulsion } \\
\text { dehydration } \\
\text { technique } \\
\text { Solvent } \\
\text { evaporation } \\
\text { technique }\end{array}$ & $\begin{array}{l}\text { Core-shell } \\
\text { structure }\end{array}$ & $\begin{array}{l}\text { Core: particle size, } 8.70 \mu \mathrm{m} \sim \\
13.59 \mu \mathrm{m} \\
\text { Entrapment rate, } 52.14 \% \sim \\
74.95 \% \\
\text { Before: } 91.44 \% \sim 99.22 \% \text { drug } \\
\text { release with } 8 \mathrm{~h} \\
\text { After: no drug release }(\mathrm{pH} 1.2), 1 \\
\sim 10 \% \text { drug release }(\mathrm{pH} 4.5 \text { and } \\
6.8), 80 \% \text { drug release }(\mathrm{pH} 7.4)\end{array}$ & (43) \\
\hline $\begin{array}{l}\text { Core (aceclofenac/pectin, } \\
1: 3 \text { to } 1: 6) / \text { shell (Eudragit } \\
\text { S-100), 1:2, 1:4, 1:6, } 1: 8 \text { or } \\
1: 10\end{array}$ & $\begin{array}{l}\text { Emulsion } \\
\text { dehydration } \\
\text { technique } \\
\text { Solvent } \\
\text { evaporation } \\
\text { technique }\end{array}$ & $\begin{array}{l}\text { Core-shell } \\
\text { structure }\end{array}$ & $\begin{array}{l}\text { Core: particle size, } 29.05 \mu \mathrm{m} \sim \\
57.48 \mu \mathrm{m} \\
\text { Entrapment rate, } 69.64 \% \sim \\
97.01 \% \\
\text { Before: } 61.12 \% \sim 99.18 \% \text { drug } \\
\text { release with } 8 \mathrm{~h} \\
\text { After: no drug release }(\mathrm{pH} 1.2), \\
8.0 \% \text { drug release }(\mathrm{pH} 6.8), 80 \% \\
\text { drug release }(\mathrm{pH} 7.4)\end{array}$ & (44) \\
\hline $\begin{array}{l}\text { Core (theophylline/alginate, } \\
1: 2, \quad 1: 3 \text { or } 1: 4) \\
\text { (theophylline/chitosan, } 1: 1, \\
1: 1.5,1: 2 \text { or } 1: 3) \\
\text { Shell: Eudragit S-100 (10\% } \\
\text { weight gain, } 20 \% \text { weight gain) }\end{array}$ & $\begin{array}{l}\text { Ionotropic } \\
\text { gelation method } \\
\text { Spray coating in } \\
\text { conventional } \\
\text { coating span }\end{array}$ & $\begin{array}{l}\text { Core-shell } \\
\text { structure }\end{array}$ & $\begin{array}{l}\text { Core: particle size, } 0.55 \mathrm{~mm} \sim \\
1.60 \mathrm{~mm} \\
\text { Entrapment rate, } 55.21 \% \sim \\
79.60 \% \\
\text { Before: }>70 \% \text { drug release with } 4 \\
\text { h } \\
\text { After: } 3.0 \text { to } 4.0 \% \text { drug release in } \\
2 \mathrm{~h},>80 \% \text { drug release }(\mathrm{pH} 7.0)\end{array}$ & (45) \\
\hline
\end{tabular}




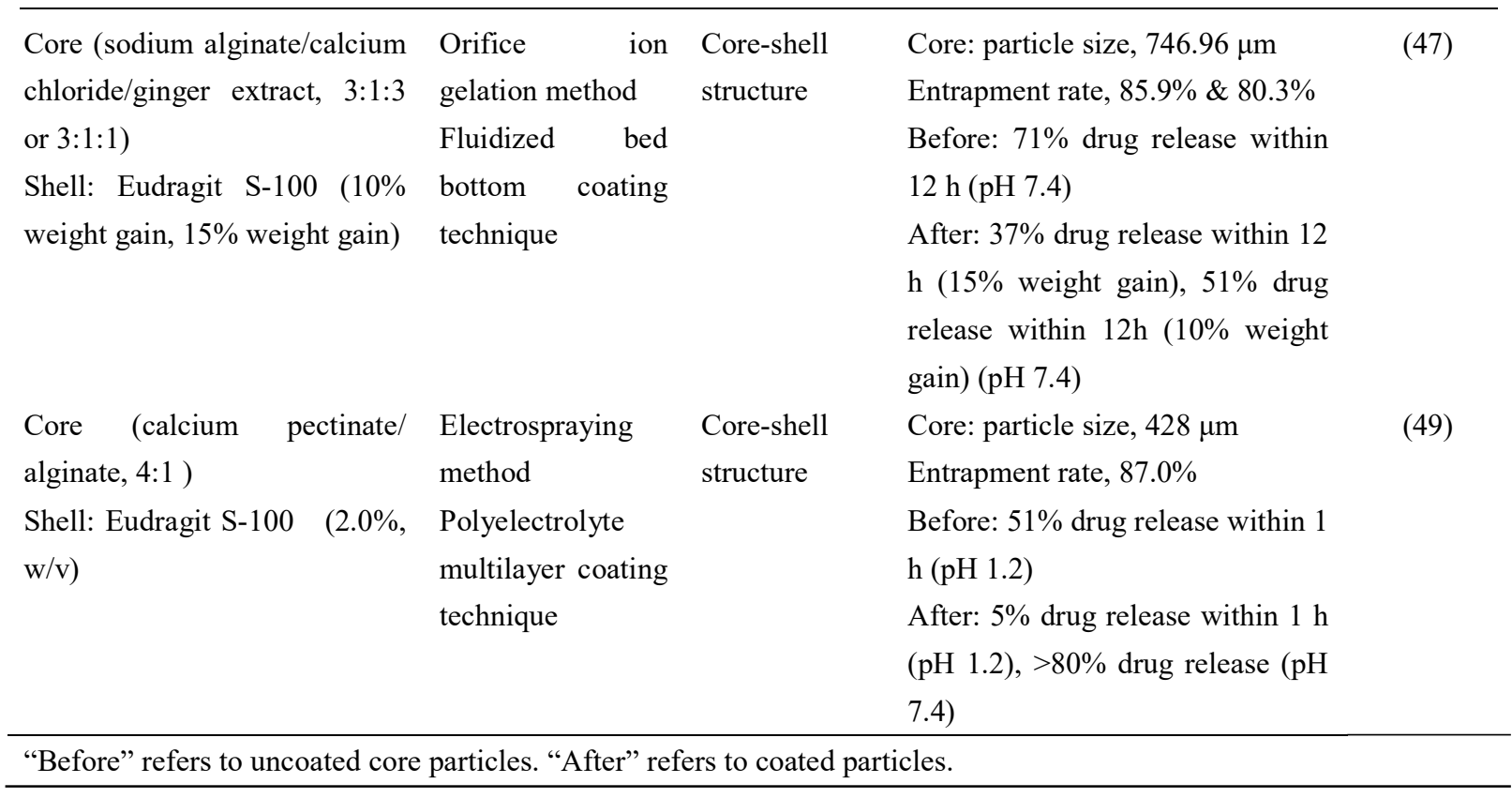

\section{Solvent evaporation technique}

The colon-targeted multiparticulate systems can be prepared by combining the emulsion-dehydration technique with the solvent evaporation method. For example, one of such systems was composed of cross-linked chitosan microspheres as inner cores and Eudragit S-100 and $\mathrm{L}-100$ as $\mathrm{pH}$-sensitive coating. Owing to the $\mathrm{pH}$-sensitive property and specific biodegradability, there was no drug release at acidic $\mathrm{pH}$ but a high drug concentration in the caecum where the coating started to dissolve at $\mathrm{pH}>7$ (40).

Under the same processing method, cross-linked chitosan microspheres were optimized for superior colon targeting (41). The results showed that polymer, cross linker, and surfactant had more prominent effects on most microsphere properties such as yield, size, entrapment, and drug release. Synergistic effects were observed between polymer and cross-linker, but polymer had a more remarkable influence on the yield. Moreover, it was confirmed that there were no any chemical interactions between drug and polymer in the preparation process. Subsequently, coating such microspheres with Eudragit S100 guaranteed the maximum level of drug in the colon (41). Similarly, several other microspheres prepared using the same methodology also showed excellent colon-targeted drug delivery (42-44).

\section{Spray technique}

In addition to the solvent evaporation method, spray coating is also a common coating method that is suitable for coating larger beads. In a study, drug-loaded beads composed of alginate and chitosan were formed by the ionotropic gelation method followed by spray coating with Eudragit S100 in a conventional coating pan (45). As the amount of polymers increased and the cross linking time decreased, the size of beads increased $(45,46)$. Such formulated beads could be applied to deliver drug to the colon effectively and $20 \%$ coating weight was sufficient to impart the beads a good enough gastro-resistant property for effective colon-specific drug release (45). Besides, fluid bed coating often gets the favor of researchers in such applications because of its high efficiency (47).

\section{Polyelectrolyte multilayer coating technique} Under some circumstances, both the solvent evaporation method and spray coating led to some aggregation of Eudragit-coated microspheres during the coating process due to the volatilization of organic solvents (48). To avoid this problem, calcium pectinate/alginate microspheres (PAMs) were prepared by an electrospraying method and then coated with Eudragit S100 in aqueous solution using a polyelectrolyte multilayer coating technique (49). In this study, the diameter of the beads could be reduced with the increasing of electrical voltage at a certain range $(7.5 \sim 15 \mathrm{kV})$. And the outer Eudragit S100 layer of PAMs that were coated with lysine in advance could be layer-by-layer coated as a result of the electrostatic attraction. 


\section{The hidden problems and solutions}

Modified single/composite particles show inestimable potentials in the modified-release system. However, in some cases, problems are encountered in the process of practical production and application, such as bitter taste and damage of the coating during compaction. On the one hand, unacceptable taste is often a nonnegligible limitation for application of some drugs. On the other hand, damage to the coating may result in a loss of the sustained release or taste masking. Thus, strategies used so far to tackle these problems were introduced as follows.

\section{Taste masking}

Unacceptable taste is a nonnegligible limitation for application of ODTs (Table 4). Some active pharmaceutical ingredients have favorable therapeutic outcome, but not suitable to be directly processed into oral dosage forms because of their bitter taste. An acceptable degree of palatability is a key issue for orally administering bitter drugs, especially to pediatric patients (50). So, there are some taste masking methodologies and technologies that have been exploited. Besides the foremost and simplest approach of adding sweeteners and/or flavors, other taste-masking techniques have also been developed, such as coating drug particles with polymers, forming inclusion complexes, using ion-exchange resins, producing multiparticulate taste-masking systems with lipids by hot-melting extrusion, and so forth (51-57). As a whole, modification of microparticles based on particle engineering, especially forming a core-shell or embedded structure, occupies an indispensable status.

\section{Formation of core-shell structures via coating} Coating with polymers

ODTs formulated to disintegrate in the oral cavity often cause an unpleasant taste and a rough sensation on the tongue during administration (58). Particle coating is a considerable surface modification method for taste masking. It can remarkably improve the stability of granules and lower the bad odor. Polymers, especially Eudragit, are widely studied for coating drug particles to effectively slow down the drug release in saliva.

Table 4. Application of particle engineering in taste masking

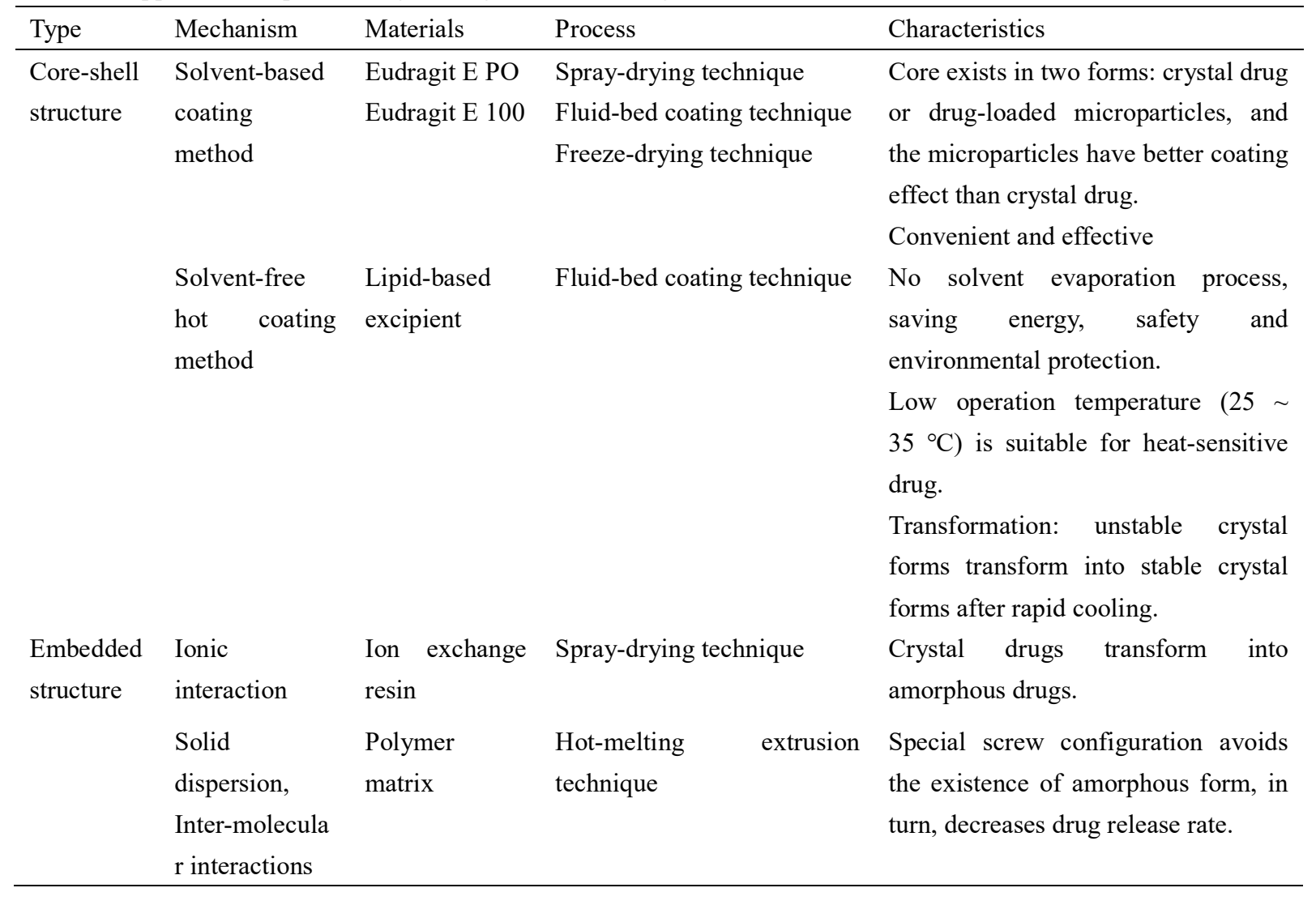


Eudragit is the brand name of a variety of
anionic, cationic, and neutral polymethacrylate-based copolymers (59). Spray drying and fluidized bed are commonly used coating methods for Eudragit. For example, in a study, Eudragit-coated drug microparticles were prepared via spray-drying, followed by being directly compacted into tablets with other excipients. The dissolution study showed that tablets containing Eudragit E100-coated microparticles had a good taste masking property by means of slowing down the release rate of drug (60).

Moreover, a novel method that prepared microparticles containing bitter nanoparticles in only one step was achieved by using a two-solution mixing nozzle-equipped spray dryer. The organic solution containing a bitter compound (quinine) and water insoluble polymer (Eudragit EPO, Eudragit S100, or EC) (1) and the aqueous solution of mannitol (2) were spray dried separately through two spray nozzles to prepare polymer-blended drug-containing nanocomposite particles and to disperse them within mannitol. The two effects worked together to prevent bitter drug molecules from touching the taste buds (61).

Based on the same principle, it is also feasible for drug particles to form core-shell structures by the fluid-bed coating with polymers. For example, coating with Eudragit E via a fluidized bed coating method made it possible to achieve taste masking of naproxen sodium (62). Additionally, the bitterness value of taste-masked particles was still below the threshold after freeze-drying and storage, indicating that the coating remained intact. On the other hand, the drug dissolution was not affected by the existence of coating film (63). Similar results were achieved in another study, demonstrating again that Eudragit E PO as drug particle coating agent in ODTs could achieve successful taste masking by the fluid-bed coating method (64).

It is an undeniable fact that polymers have a very excellent effect of taste masking; however, some of their properties are unsuitable, which directly affect their range of application. For example, Eudragit E PO is insoluble in neutral and basic $\mathrm{pH}$ but soluble in acidic $\mathrm{pH}$ (65). In a try to overcome this, citric acid was used as both $\mathrm{pH}$-modifying agent and taste-masking agent with Eudragit E PO (66). In addition, it was also found that directly coating irregular-shaped drug particles with polymers was promising in achieving a wide size distribution for further application in ODT platforms. Moreover, when prepared by the fluidized bed process, the coated microgranules were much more effectively taste-masked than coated drug crystals $(65,66)$. Finally, although coating with polymers might impair palatability, it can be improved by coating an outer layer containing flavors like mannitol (58).

\section{Coating with lipids}

As mentioned above, polymer coatings play a vital role in taste masking. In general, polymers must be dissolved or dispersed in aqueous or organic solvents before coating. By contrast, lipids present an attractive alternative to polymeric coatings since melting is the only requirement before their direct application onto the substrate. Namely, no solvent evaporation is required, and thus, powders having high specific surface areas can be coated rapidly (67).

In a study, solvent-free hot coating with lipid-based excipients was used to manufacture taste-masked multiparticulate systems that had a stable immediate release profile. A thermosensitive drug was used as model drug due to low operating temperatures $\left(25-35^{\circ} \mathrm{C}\right)$ in the process of fluid bed hot-melt spray coating. The addition of polysorbate 65 succeeded in accelerating the transformation of crystal forms of tripalmitin (unstable $\alpha$-form transformed into stable $\beta$-form after rapid cooling). This polymorphic transformation effectively ensured the crystal and dissolution stability during storage. Moreover, the addition of polysorbate 65 maintained the immediate release profile of the water-soluble drug as well. Both in vivo and in vitro results showed that the coating amount, emulsifier content, and spray pressure were the main critical parameters $(68,69)$.

\section{Others}

Without using any polymers or lipids, a novel coating design was presented for taste masking (70). Baicalin and andrographolide were both active ingredients of Gankeshuangqing dispersible tablets and the former was much less bitter than the latter. The composite particles were prepared by co-milling, where baicalin was coated on the surface of andrographolide to decrease bitterness. Moreover, this coating method can not only achieve taste masking, but also greatly decrease the use of excipients and increase the content of drugs (70). 
Formation of embedded structures with hot-melting extrusion technique

In addition to surface coating with polymers, embedded structures formed by the hot-melting extrusion (HME) technique have been accepted as an efficient way of taste masking. Mechanisms include the formation of solid dispersions and inter-molecular interactions (71).

In a study, ibuprofen was dispersed within a methacrylate copolymer matrix to produce solid dispersions by HME (72). The granules produced were directly compacted with superdisintegrants into ODTs. Excellent taste-masking was achieved without compromising tablet palatability. Subsequently, the masking efficiency of HME formulations that contained high paracetamol loading in Eudragit EPO or Kollidon VA64 was evaluated. Taste improvement was observed with the existence of any of the two polymers and the optimal masking effect was achieved by VA64 at $30 \%$ drug loading (73).

On the other hand, enhanced drug-polymer interactions can be achieved by HME, which is also favorable to mask the bitter taste of APIs. For example, extrudates were produced by HME using water soluble cationic model drugs and various grades of anionic polymers (Eudragit L100 and Eudragit L100-55 (Acryl EZE)). It was found that the products not only had a significant taste masking effect, but also showed fast release for most drug substances (74-76).

It is well known that amorphous form dissolves more quickly than crystalline form. A study indicated that the screw configuration of HME had a marked effect on the taste masking efficiency of the formulations by means of altering the physical state of the API and avoiding the existence of amorphous form (77). In contrast, spray-dried powders had a tendency to exist in amorphous form, and thus, were not conducive to the occurrence of taste masking (78).

In addition, adding $\mathrm{pH}$ regulator such as calcium carbonate into the extruded formulations could not only prevent the dissolution of drug under oral conditions ( $\mathrm{pH} 6.8$ ), but also promote its dissolution under gastric conditions $(\mathrm{pH} 2)$ (77). Based on the same methodology, ethylcellulose (EC) coupled with a suitable plasticizer (triethyl citrate) as carrier was formulated with $\mathrm{pH}$ dependent pore formers such as calcium phosphate, calcium carbonate, and magnesium oxide. Due to being only soluble in an acidic environment, these pore formers led to a slow drug release in saliva but rapid gastric release (79). In another study, HME of Kleptose Linecaps DE17 was achieved only in the presence of xylitol as plasticizer at $15 \% \mathrm{w} / \mathrm{w}$ level. And as for the select of a pore former, formulations with inorganic salts showed slightly better taste masking efficiency (80).

\section{Protection in tableting coated pellets}

Multiparticulates can achieve multifunctional properties by coating. With regard to the final dosage form, coated multiparticulates are commonly formulated into single-unit dosage forms, e.g., filling them into capsules or compacting them into tablets. However, what should not be ignored is that compacting coated pellets may bring about some issues. The most important one is that the integrity of coating film may be damaged under the compaction process. Moreover, minor damage to the coating film might be enough to result in a significant loss of its function, like sustained release or taste masking. Therefore, the coating can deform, but should not rupture during compaction (81). So far, some materials and methods have been developed to tackle this problem well (Figure 3).

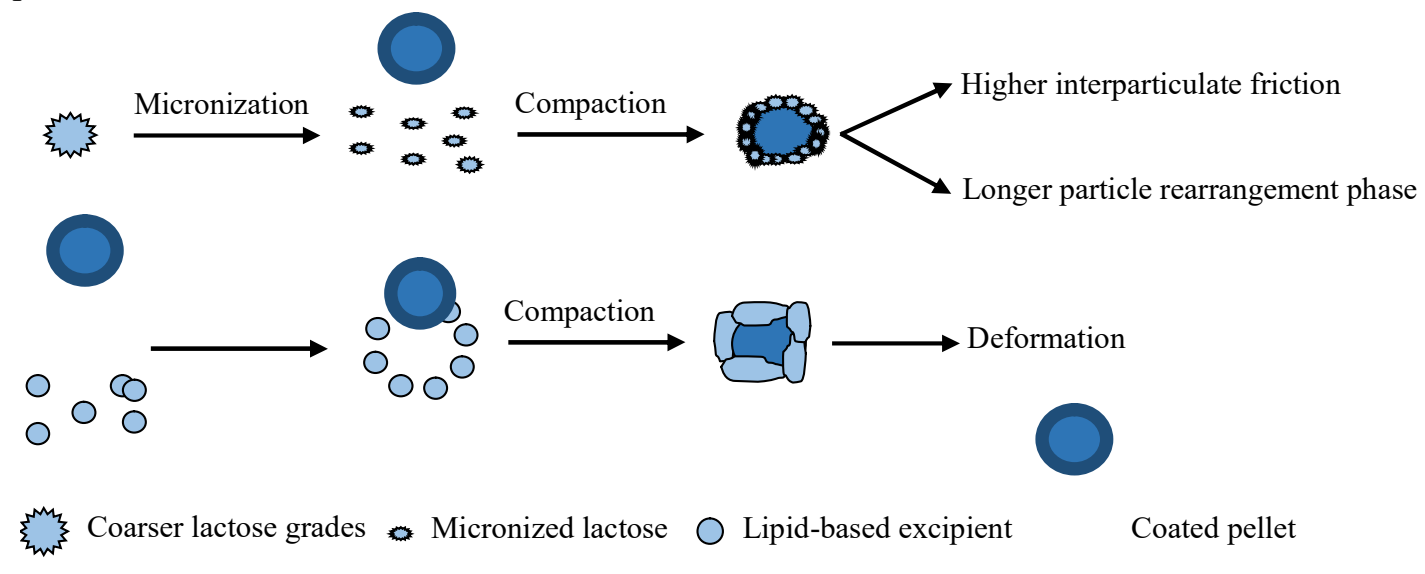

Figure 3. Protection mechanisms in tableting coated pellets 


\section{Micronized pharmaceutical additives}

To decrease mechanical damage of the coating film during compaction, various pharmaceutical additives as cushioning agents were investigated. It was found that the particle size of additives was one of the most important factors determining their cushioning effect. The additives with small particle size were superior in protecting the coating film from damage. In general, $20 \mu \mathrm{m}$ appeared to be a critical value of particle size for each additive to achieve good protective effect (82).

Micronized lactose (ML) had a cushioning effect during the tableting of multiparticulates and the degree of coating damage increased linearly with the increasing of its median particle size (83, 84). It was observed that ML could more effectively protect pellet coats from damage than coarser lactose grades that caused deeper and larger surface indentation on the coating film during compaction. Moreover, the protective effect conferred by ML was believed to be not only through dimensional delimitations, but also by higher interparticulate friction and longer particle rearrangement phase (83). Although spray drying of ML led to slight reduction in the cushioning effect, this processing method significantly improved its physicomechanical properties. Eventually, co-spray drying ML with suitable polymers, especially HPMC, not only retained the cushioning effect of ML, but also enhanced its compressibility and compactibility to a certain degree (84).

In addition to the modification of single-component particles, the design of composite particles is another effective way to achieve acceptable cushioning actions. Spray-dried aggregates of ML and mannitol as cushioning agent were systematically examined. Intriguingly, the final formulation was consolidated by plastic deformation, meaning that extending the dwell time in the compaction cycle could enhance tablet mechanical strength without exacerbating coating damage during rotary tableting. Note that the distribution of coated pellets in the die was a non-negligible factor that might accentuate the extent of coat damage due to uneven force distribution. Therefore, the continuous percolating network of cushioning agent and an appropriately applied compaction pressure were two keys to protect the integrity of the coating film (85). Some other composite particles, such as porous calcium phosphate (DCP)/MCC pellets and lactose/MCC pellets, could also maintain the original shape and release characteristics of drug pellets when they were tableted together (86).

\section{Lipid-based additives}

Wax beads were used as cushioning agent because of their plastic deformability. In a study, the dissolution profile of coated pellets before and after compaction was considered as the evaluation standard of cushioning properties. The results showed that only the tablet formulations including wax/starch had the capability of protecting the coating from damage (87). Note that although wax beads showed a superior cushioning action, they also caused some other problems. For example, the tablets formulated with wax beads had difficulties in dissolution and disintegration. Luckily, the cushioning beads containing disintegrants such as Explotab can achieve rapid disintegration while still provide enough protection for the coating film (87). Another problem is that the beads, either coated or wax, lacked good bonding under tableting (88). In view of this, the polymethacrylate-coated beads were overcoated with (i) HPMC as binder to improve bead binding and compactability and (ii) lactose/sodium starch glycolate as cushioning agent/disintegrant to allow the whole coating not to be broken during compaction. The addition of binder and disintegrant greatly solved the poor physicomechanical property of coated beads and the poor disintegration of tablets, respectively, while not affecting the cushioning effect (89).

Wax beads mentioned above were wet granulated from a mixture of glyceryl palmitostearate and other materials such as MCC (88). It was found that stearic acid was a potential lipid-based cushioning agent and usually combined with other materials to protect completeness of the coating together. For example, cushioning pellets made up of stearic acid/MCC $(4: 1, w / w)$ could effectively avoid fracture of the coating film during compaction (90).

In addition, for multiparticulate tablet formulations consisting of placebo beads and drug-loaded beads, segregation is often an inevitable problem. In general, the lipid-based placebo beads prepared by extrusion-spheronized technology can effectively protect the coating integrity of drug beads under a series of different tableting conditions. Particularly, the glycerol monostearate-based ones show great potentials as cushioning agent for coated drug beads (91). However, blend segregation is likely occurred due to the differences in particle size and density between drug beads and placebo beads. Therefore, 
an optimized compaction pressure range together with a reasonable drug bead/placebo bead ratio (e.g., 50:50) was suggested $(91,92)$.

Besides, blending stearic acid with Explotab had been demonstrated to have additive protection for the coated beads as well (93). Compared with physical mixtures, co-spray dried fillers containing stearic acid were effective at protecting coated pellets from compaction-induced damage without sacrifice of disintegratability. This should be benefited from the homogenization and the incorporation of stearic acid in the cushioning agents by the co-processing. Furthermore, under the same force and stearic acid level, co-processed fillers showed higher compaction performance than the corresponding physical blends. Therefore, this co-spray drying method served as a step that not only ensured the cushioning effect of materials, but also good tableting performance and acceptable tablet disintegration time (94).

\section{CONCLUSION}

Particle engineering plays an important role in a variety of modified-release delivery systems (e.g., fast-release systems, sustained-release systems, and targeted-release systems). In addition, it is also used to facilitate production and develop new preparation functions. Modification of fundamental properties of particles (such as size, shape, structure, and crystalline form) via particle engineering can effectively improve their functional performances. A new structure formed can bring a functional improvement or development.

Porous structures can accelerate the penetration of dissolution media into fast-release systems, resulting in shortened disintegration time and, in most cases, improved bioavailability. However, for some water-insoluble drugs, accelerating disintegration is not enough to effectively improve their bioavailability because they're just quickly scattered but not dissolved. Therefore, additional techniques like cyclodextrin inclusion are needed to markedly improve solubility of such drugs. On the other hand, overhigh porosity may bring about a poor tableting property. At this point, co-processing with porous silica or modifying drug particles via integrated crystal and particle engineering might be a way to tackle the formability issue.

Core-shell structures formed with special coating materials via various processing techniques are the key to sustained-release systems and targeted-release systems. In other words, coating materials are usually considered to be the main factor of achieving a special function. Thereinto, lipids and polymers are widely used functional coating materials. Intriguingly, when two or more principles are used together, additive synergism could happen. Note that the inner core is also a crucial factor needing to be taken into consideration seriously since its composition, shape, and size can indirectly affect the ultimate functional properties in most cases.

Bitter taste and coating damage are two main problems that might be met in the practical applications mentioned above. Forming core-shell or embedded structures is the main approach to effectively masking bad flavors. And, cushioning agents like micronized lactose, wax beads, and stearic acids have been proved to have excellent buffering effects to preserve the integrity of the functional coating film of multiparticulates during tableting.

All in all, although many techniques show better experimental results, it must be admitted that most of them are only tested in the laboratory level. Therefore, in-depth studies need to be carried out to make them more suitable for industrial production.

\section{ACKNOWLEDGEMENT}

This work was sponsored by Natural Science Foundation of Shanghai (18ZR1439800), the Xinglin Young Scholar Program of Shanghai University of Traditional Chinese Medicine (A1-U17205010416), and the graduate student innovation project of Shanghai University of Traditional Chinese Medicine (Y201837).

\section{DECLARATION OF INTEREST}

The authors report no declarations of interest.

\section{REFERENCE}

1. Vehring R. Pharmaceutical particle engineering via spray drying. Pharm Res. 2008; 25: 999-1022. DOI: $10.1007 / \mathrm{s} 11095-007-9475-1$

2. Rojas J, Buckner I, Kumar V. Co-proccessed excipients with enhanced direct compression functionality for improved tableting performance. Drug Dev Ind Pharm. 2012; 38: 1159-1170. DOI: 10.3109/03639045.2011.645833

3. Yassin S, Goodwin DJ, Anderson A, Sibik J, Wilson DI, Gladden LF, Zeitler JA. The Disintegration Process in Microcrystalline Cellulose Based Tablets, Part 1: Influence of 
Temperature, Porosity and Superdisintegrants. J Pharm Sci. 2015; 104: 3440-3450. DOI: 10.1002/jps. 24544

4. Amirali E, Morteza S, Timothy L. Developing a new production process for high-porosity lactose particles with high degrees of crystallinity. Powder Technol. 2015; 272: 45-53. DOI: 10.1016/j.powtec.2014.11.033

5. Gervelas C, Serandour AL, Geiger S, Grillon G, Fritsch P, Taulelle C, Le Gall B, Benech H, Deverre JR, Fattal E, Tsapis N. Direct lung delivery of a dry powder formulation of DTPA with improved aerosolization properties: effect on lung and systemic decorporation of plutonium. J Control Release. 2007; 118: 78-86. DOI: 10.1016/j.jconrel.2006.11.027

6. El-Sherif DM, Wheatley MA. Development of a novel method for synthesis of a polymeric ultrasound contrast agent. J Biomed Mater Res A. 2003; 66: 347-355. DOI: 10.1002/jbm.a.10586

7. Al-Khattawi A, Koner J, Rue P, Kirby D, Perrie Y, Rajabi-Siahboomi A, Mohammed AR. A pragmatic approach for engineering porous mannitol and mechanistic evaluation of particle performance. Eur J Pharm Biopharm. 2015; 94: 1-10. DOI: 10.1016/j.ejpb.2015.04.011

8. Wang L, Zeng F, Zong L. Development of orally disintegrating tablets of Perphenazine/hydroxypropyl- $\beta$-cyclodextrin inclusion complex. Pharm Dev Technol. 2013; 18: 1101-1110. DOI: $10.3109 / 10837450.2012 .700932$

9. Zeng F, Wang L, Zhang W, Shi K, Zong L. Formulation and in vivo evaluation of orally disintegrating tablets of clozapine/hydroxypropyl- $\beta$-cyclodextrin inclusion complexes. AAPS PharmSciTech. 2013; 14: 854-860. DOI: 10.1208/s12249-013-9973-x

10. Desai C, Prabhakar B. Development and evaluation of orally disintegrating tablets of cilostazol- $\beta$-cyclodextrin inclusion complexes. Drug Dev Ind Pharm. 2015; 41: 1589-1607. DOI: 10.3109/03639045.2014.972413

11. Salústio PJ, Feio G, Figueirinhas JL, Pinto JF, Cabral Marques HM. The influence of the preparation methods on the inclusion of model drugs in a beta-cyclodextrin cavity. Eur J Pharm Biopharm. 2009; 71: 377-386. DOI: 10.1016/j.ejpb.2008.09.027

12. Ainurofiq A, Choiri S. Development and optimization of a meloxicam $/ \beta$-cyclodextrin complex for orally disintegrating tablet using statistical analysis. Pharm Dev Technol. 2018; 23: 464-475. DOI: 10.1080/10837450.2016.1264418

13. Obaidat AA, Khanfar RA, Khawam MN. The effect of $\beta$-cyclodextrin on the solubility and dissolution rate of meloxicam and investigation of the driving force for complexation using molecular modeling. J. Incl. Phenom. Macrocycl. 2009; 63: 273-279. DOI: $10.1007 / \mathrm{s} 10847-008-9517-2$
14. Kande KV, Kotak DJ, Degani MS, Kirsanov D, Legin A, Devarajan PV. Microwave-Assisted Development of Orally Disintegrating Tablets by Direct Compression. AAPS PharmSciTech. 2017;18: 2055-2066. DOI: 10.1208/s12249-016-0683-Z

15. Ainurofiq A, Choiri S, Azhari MA, Siagian CR, Suryadi BB, Prihapsara F, Rohmani S. Improvement of Meloxicam Solubility Using a $\beta$-Cyclodextrin Complex Prepared via the Kneading Method and Incorporated into an Orally Disintegrating Tablet. Adv Pharm Bull. 2016; 6: 399-406. DOI: 10.15171/apb.2016.052

16. Al-khattawi A, Mohammed AR. Compressed orally disintegrating tablets: excipients evolution and formulation strategies. Expert Opin Drug Deliv. 2013; 10: 651-663. DOI: 10.1517/17425247.2013.769955

17. Tanimura S, Tahara K, Takeuchi H. Spray-dried composite particles of erythritol and porous silica for orally disintegrating tablets prepared by direct tableting. Powder Technol. 2015, 286: 444-450. DOI: $10.1016 /$ j.powtec.2015.08.011

18. Adeoye O, Alebiowu G. Evaluation of coprocessed disintegrants produced from tapioca starch and mannitol in orally disintegrating paracetamol tablet. Acta Pol Pharm. 2014; 71: 803-811.

19. Wang C, Hu S, Sun CC. Expedited development of a high dose orally disintegrating metformin tablet enabled by sweet salt formation with acesulfame. Int J Pharm. 2017; 532: 435-443. DOI 10.1016/j.ijpharm.2017.08.100

20. Wang C, Hu S, Sun CC. Expedited Development of Diphenhydramine Orally Disintegrating Tablet through Integrated Crystal and Particle Engineering. Mol Pharm. 2017; 14: 3399-3408. DOI: 10.1021 acs.molpharmaceut.7b00423

21. Pham L, Christensen JM. Preparation of acetaminophen capsules containing beads prepared by hot-melt direct blend coating. Pharm Dev Technol. 2014; 19: 91-102. DOI: 10.3109/10837450.2012.757783

22. Yang Y, Shen L, Li J, Shan WG. Preparation and evaluation of metoprolol tartrate sustained-release pellets using hot melt extrusion combined with hot melt coating. Drug Dev Ind Pharm. 2017; 43: 939-946. DOI: 10.1080/03639045.2017.1287715

23. Aburahma MH, Badr-Eldin SM. Compritol 888 ATO: a multifunctional lipid excipient in drug delivery systems and nanopharmaceuticals. Expert Opin Drug Deliv. 2014; 11: 1865-1883. DOI: 10.1517/17425247.2014.935335

24. Kim HJ, Shin DH, Lim EA, Kim JS. Sustained-release formulation of sarpogrelate hydrochloride. Arch Pharm Res. 2015; 38: 35-41. DOI: $10.1007 /$ s12272-014-0415-4

25. Sakarkar DM, Dorle AK, Mahajan NM, Sudke SG. Design of sustained release pellets of ferrous fumarate using cow ghee as hot-melt coating agent Int J Pharm Investig. 2013; 3: 151-156. DOI: 
10.4103/2230-973X.119225

26. Knezevic Z, Gosak D, Hraste M, Rausl D, Khan MZ. Application of hot-melt coating process for designing a lipid based controlled release drug delivery system for highly aqueous soluble drugs. Chem Pharm Bull (Tokyo). 2009; 57: 464-471. DOI: $10.1248 / \mathrm{cpb} .57 .464$

27. Yang ZY, Lu Y, Tang X. Pseudoephedrine hydrochloride sustained-release pellets prepared by a combination of hot-melt subcoating and polymer coating. Drug Dev Ind Pharm. 2008; 34 : 1323-1330. DOI: 10.1080/03639040802084938

28. Yan HX, Zhang SS, He JH, Liu JP. Application of ethyl cellulose, microcrystalline cellulose and octadecanol for wax based floating solid dispersion pellets. Carbohydr Polym. 2016; 148: 143-152. DOI: 10.1016/j.carbpol.2016.04.050

29. Li Z, Xu H, Li S, Li Q, Zhang W, Ye T, Yang X, Pan W. A novel gastro-floating multiparticulate system for dipyridamole (DIP) based on a porous and low-density matrix core: in vitro and in vivo evaluation. Int J Pharm. 2014; 461: 540-548. DOI: 10.1016/j.ijpharm.2013.12.024

30. Ha JM, Kim JY, Oh TO, Rhee YS, Chi SC, Kuk H, Park CW, Park ES. Preparation and evaluation of sustained-release doxazosin mesylate pellets. Chem Pharm Bull (Tokyo). 2013; 61: 371-378.

31. Kállai N, Luhn O, Dredán J, Kovács K, Lengyel M, Antal I. Evaluation of drug release from coated pellets based on isomalt, sugar, and microcrystalline cellulose inert cores. AAPS PharmSciTech. 2010; 11: 383-391. DOI: 10.1208/s12249-010-9396-x

32. Biswas N, Sahoo RK. Tapioca starch blended alginate mucoadhesive-floating beads for intragastric delivery of Metoprolol Tartrate. Int J Biol Macromol. 2016; 83: 61-70. DOI: 10.1016/j.ijbiomac.2015.11.039

33. Tomuţă I, Leucuţa SE. Development and in vitro evaluation of multiparticulate sustained release carbamazepine formulation. Acta Pol Pharm. 2012; 69: 951-964.

34. Wang B, Friess W. Formation of mannitol core microparticles for sustained release with lipid coating in a mini fluid bed system. Eur J Pharm Biopharm. 2017; 120: 126-132. DOI: 10.1016/j.ejpb.2017.09.003

35. Yu P, Zhang S, Zhang W, Yang J, Lu J, Liu J. Tanshinol sustained-release pellets with absorption enhancer: optimization, characterization, pharmacokinetics and pharmacodynamics. Drug Dev Ind Pharm. 2017; 43: 1093-1102. DOI: 10.1080/03639045.2017.1291671

36. Hoashi Y, Tozuka Y, Takeuchi H. Solventless dry powder coating for sustained drug release using mechanochemical treatment based on the tri-component system of acetaminophen, carnauba wax and glidant. Drug Dev Ind Pharm. 2013; 39: 259-265. DOI: 10.3109/03639045.2012.673625

37. Kondo K, Ito N, Niwa T, Danjo K. Design of sustained release fine particles using two-step mechanical powder processing: particle shape modification of drug crystals and dry particle coating with polymer nanoparticle agglomerate. Int J Pharm. 2013; 453: 523-532. DOI: 10.1016/j.ijpharm.2013.06.028

38. Nakamura $\mathrm{S}$, Sakamoto $\mathrm{T}$, Ito $\mathrm{T}$, Kabasawa $\mathrm{K}$, Yuasa H. Preparation of Controlled-Release Fine Particles Using a Dry Coating Method. AAPS PharmSciTech. 2016; 17: 1393-1403. DOI: 10.1208/s12249-015-0475-x

39. Asghar LF, Chandran S. Multiparticulate formulation approach to colon specific drug delivery: current perspectives. J Pharm Pharm Sci. 2006; 9: 327-338.

40. Chourasia MK, Jain SK. Design and development of multiparticulate system for targeted drug delivery to colon. Drug Deliv. 2004; 11: 201-207. DOI: $10.1080 / 10717540490445955$

41. Prajapati B, Jena PK, Mehta T, Seshadri S. Preparation and optimization of moxifloxacin microspheres for colon targeted delivery using quality by design approach: in vitro and in vivo study. Curr Drug Deliv. 2016; 13: 1021-1033. DOI: 10.2174/1567201813666160512145625

42. Paharia A, Yadav AK, Rai G, Jain SK, Pancholi SS Agrawal GP. Eudragit-coated pectin microspheres of 5-fluorouracil for colon targeting. AAPS PharmSciTech. 2007; 8: 12. DOI: 10.1208/pt0801012

43. Vaidya A, Jain A, Khare P, Agrawal RK, Jain SK. Metronidazole loaded pectin microspheres for colon targeting. J Pharm Sci. 2009; 98: 4229-4236. DOI: $10.1002 /$ jps.21742

44. Ramasamy T, Ruttala HB, Shanmugam S, Umadevi SK. Eudragit-coated aceclofenac-loaded pectin microspheres in chronopharmacological treatment of rheumatoid arthritis. Drug Deliv. 2013; 20: 65-77. DOI: 10.3109/10717544.2012.762434

45. Khan MS, Sridhar BK, Srinatha A. Development and Evaluation of $\mathrm{pH}$-Dependent Micro Beads for Colon Targeting. Indian J Pharm Sci. 2010; 72: 18-23. DOI: 10.4103/0250-474X.62230

46. Jain SK, Jain A, Gupta Y, Ahirwar M. Design and development of hydrogel beads for targeted drug delivery to the colon. AAPS PharmSciTech. 2007; 8: E56. DOI: 10.1208/pt0803056

47. Deol PK, Kaur IP. J Drug Target. Improving the therapeutic efficiency of ginger extract for treatment of colon cancer using a suitably designed multiparticulate system. J Drug Target. 2013; 21: 855-865. DOI: 10.3109/1061186X.2013.829076

48. Perumal D. Microencapsulation of ibuprofen and Eudragit RS 100 by the emulsion solvent diffusion technique. Int J Pharm. 2001; 218: 1-11. DOI: 10.1016/S0378-5173(00)00686-4

49. Hsu FY, Yu DS, Huang CC. Development of $\mathrm{pH}$-sensitive pectinate/alginate microspheres for 
colon drug delivery. J Mater Sci Mater Med. 2013; 24: 317-323. DOI: $10.1007 / \mathrm{s} 10856-012-4798-9$

50. Sohi H, Sultana Y, Khar RK. Taste masking technologies in oral pharmaceuticals: recent developments and approaches. Drug Dev Ind Pharm. 2004; 30: 429-448. DOI: 10.1081/DDC-120037477

51. Mostafavi SA, Varshosaz J, Arabian S. Formulation development and evaluation of metformin chewing gum with bitter taste masking. Adv Biomed Res. 2014; 3: $92 . \quad$ DOI: 10.4103/2277-9175.129362

52. Choi du H, Kim NA, Nam TS, Lee S, Jeong SH. Evaluation of taste-masking effects of pharmaceutical sweeteners with an electronic tongue system. Drug Dev Ind Pharm. 2014; 40: 308-317. DOI: 10.3109/03639045.2012.758636

53. Agresti C, Tu Z, Ng C, Yang Y, Liang JF. Specific interactions between diphenhydramine and alpha-helical poly(glutamic acid)--a new ion-pairing complex for taste masking and $\mathrm{pH}$-controlled diphenhydramine release. Eur $\mathrm{J}$ Pharm Biopharm. 2008; 70: 226-233. DOI: 10.1016/j.ejpb.2008.04.004

54. Taki M, Tagami T, Ozeki T. Preparation of polymer-blended quinine nanocomposite particles by spray drying and assessment of their instrumental bitterness-masking effect using a taste sensor. Drug Dev Ind Pharm. 2017; 43: 715-722. DOI: $10.1080 / 03639045.2016 .1200070$

55. Samprasit W, Akkaramongkolporn P, Ngawhirunpat T, Rojanarata T, Opanasopit P. Formulation and evaluation of meloxicam oral disintegrating tablet with dissolution enhanced by combination of cyclodextrin and ion exchange resins. Drug Dev Ind Pharm. 2015; 41: 1006-1016. DOI: $10.3109 / 03639045.2014 .922573$

56. Alayoubi A, Daihom B, Adhikari H, Mishra S, Helms R, Almoazen H. Development of a taste-masked oral suspension of clindamycin $\mathrm{HCl}$ using ion exchange resin Amberlite IRP 69 for use in pediatrics. Drug Dev Ind Pharm. 2016; 42: 1579-1589.

DOI: 10.3109/03639045.2016.1160102

57. Petrovick GF, Breitkreutz J, Pein-Hackelbusch M. Taste-masking properties of solid lipid based micropellets obtained by cold extrusion-spheronization. Int $\mathrm{J}$ Pharm. 2016; 506:361-370. DOI: 10.1016/j.ijpharm.2016.04.058

58. Kimura S, Uchida S, Kanada K, Namiki N. Effect of granule properties on rough mouth feel and palatability of orally disintegrating tablets. Int $\mathrm{J}$ Pharm. 2015; 484: 156-162. DOI: 10.1016/j.ijpharm.2015.02.023

59. Thakral S, Thakral NK, Majumdar DK. Eudragit: a technology evaluation. Expert Opin Drug Deliv. 2013; $\quad 10$ : 131-149. DOI: 10.1517/17425247.2013.736962

60. Brniak W, Maślak E, Jachowicz R. Orodispersible films and tablets with prednisolone microparticles.
Eur J Pharm Sci. 2015; 75: 81-90. DOI: 10.1016/j.ejps.2015.04.006

61. Taki M, Tagami T, Ozeki T. Preparation of polymer-blended quinine nanocomposite particles by spray drying and assessment of their instrumental bitterness-masking effect using a taste sensor. Drug Dev Ind Pharm. 2017; 43: 715-722. DOI: 10.1080/03639045.2016.1200070

62. Stange U, Führling C, Gieseler H. Taste masking of naproxen sodium granules by fluid-bed coating. Pharm Dev Technol. 2014; 19: 137-147. DOI: $10.3109 / 10837450.2012 .757784$

63. Stange U, Führling C, Gieseler H. Formulation, preparation, and evaluation of novel orally disintegrating tablets containing taste-masked naproxen sodium granules and naratriptan hydrochloride. J Pharm Sci. 2014; 103: 1233-1245. DOI: $10.1002 / j p s .23896$

64. Drašković M, Medarević D, Aleksić I, Parojčić J. In vitro and in vivo investigation of taste-masking effectiveness of Eudragit E PO as drug particle coating agent in orally disintegrating tablets. Drug Dev Ind Pharm. 2017; 43: 723-731. DOI: 10.1080/03639045.2016.1220572

65. Xu M, Heng PW, Liew CV. Evaluation of coat uniformity and taste-masking efficiency of irregular-shaped drug particles coated in a modified tangential spray fluidized bed processor. Expert Opin Drug Deliv. 2015; 12: 1597-1606. DOI: $10.1517 / 17425247.2015 .1054278$

66. Guhmann $M$, Preis $M$, Gerber F, Pöllinger N, Breitkreutz J, Weitschies W. Design, development and in-vitro evaluation of diclofenac taste-masked orodispersible tablet formulations. Drug Dev Ind Pharm. 2015; 41: 540-551. DOI: 10.3109/03639045.2014.884122

67. Jannin V, Cuppok Y. Hot-melt coating with lipid excipients. Int J Pharm. 2013; 457: 480-487. DOI: 10.1016/j.ijpharm.2012.10.026

68. Lopes DG, Garsuch V, Becker K, Paudel A, Stehr M, Zimmer A, Salar-Behzadi S. Improving the granule strength of roller-compacted ibuprofen sodium for hot-melt coating processing. Int $\mathrm{J}$ Pharm. 2016; 510: 285-295. DOI: 10.1016/j.ijpharm.2016.06.049

69. Becker K, Saurugger EM, Kienberger D, Lopes D, Haack D, Köberle M, Stehr M, Lochmann D, Zimmer A, Salar-Behzadi S. Advanced stable lipid-based formulations for a patient-centric product design. Int J Pharm. 2016; 497: 136-149. DOI: 10.1016/j.ijpharm.2015.11.039

70. Han X, Zhang DK, Zhang F, Lin JZ, Jiang H, Lan Y, Xiong X, Han L, Yang M, Fu CM. A Novel Strategy for Bitter Taste Masking of Gankeshuangqing Dispersible Tablets Based on Particle Coating Technology. Pharmacogn Mag. 2017; 13: 400-406. DOI: 10.4103/pm.pm_240_16

71. Maniruzzaman M, Boateng JS, Chowdhry BZ, Snowden MJ, Douroumis D. A review on the taste masking of bitter APIs: hot-melt extrusion (HME) 
evaluation. Drug Dev Ind Pharm. 2014; 40: 145-156. DOI: $10.3109 / 03639045.2013 .804833$

72. Gryczke A, Schminke S, Maniruzzaman M, Beck J, Douroumis D. Development and evaluation of orally disintegrating tablets (ODTs) containing Ibuprofen granules prepared by hot melt extrusion. Colloids Surf B Biointerfaces. 2011; 86: 275-284. DOI: $10.1016 /$ j.colsurfb.2011.04.007

73. Maniruzzaman M, Boateng JS, Bonnefille M, Aranyos A, Mitchell JC, Douroumis D. Taste masking of paracetamol by hot-melt extrusion: an in vitro and in vivo evaluation. Eur J Pharm Biopharm. 2012; 80: 433-442. DOI: 10.1016/j.ejpb.2011.10.019

74. Maniruzzaman M, Bonnefille $\mathrm{M}$, Aranyos A, Snowden MJ, Douroumis D. An in-vivo and in-vitro taste masking evaluation of bitter melt-extruded drugs. J Pharm Pharmacol. 2014; 66: 323-337. DOI: 10.1111/jphp. 12169

75. Alshehri SM, Park JB, Alsulays BB, Tiwari RV, Almutairy B, Alshetaili AS, Morott J, Shah S, Kulkarni V, Majumdar S, Martin ST, Mishra S, Wang L, Repka MA. Mefenamic acid taste-masked oral disintegrating tablets with enhanced solubility via molecular interaction produced by hot melt extrusion technology. J Drug Deliv Sci Technol. 2015; 27: 18-27. DOI: 10.1016/j.jddst.2015.03.003

76. Maniruzzaman M, Douroumis D. An in-vitro-in-vivo taste assessment of bitter drug: comparative electronic tongues study. J Pharm Pharmacol. 2015; 67: 43-55. DOI: 10.1111/jphp. 12319

77. Morott JT, Pimparade M, Park JB, Worley CP, Majumdar S, Lian Z, Pinto E, Bi Y, Durig T, Repka MA. The effects of screw configuration and polymeric carriers on hot-melt extruded taste-masked formulations incorporated into orally disintegrating tablets. J Pharm Sci. 2015; 104: 124-134. DOI: 10.1002/jps.24262

78. Münster M, Schoch C, Schmidt C, Breitkreutz J. Multiparticulate system combining taste masking and immediate release properties for the aversive compound praziquantel. Eur J Pharm Sci. 2017; 109: 446-454. DOI: 10.1016/j.ejps.2017.08.034

79. Pimparade MB, Morott JT, Park JB, Kulkarni VI, Majumdar S, Murthy SN, Lian Z, Pinto E, Bi V, Durig T, Murthy R, Shivakumar HN, Vanaja K, Kumar PC, Repka MA. Development of taste masked caffeine citrate formulations utilizing hot melt extrusion technology and in vitro-in vivo evaluations. Int J Pharm. 2015; 487: 167-176. DOI: 10.1016/j.ijpharm.2015.04.030

80. Juluri A, Popescu C, Zhou L, Murthy RN, Gowda VK, Chetan Kumar P, Pimparade MB, Repka MA, Murthy SN. Taste Masking of Griseofulvin and Caffeine Anhydrous Using Kleptose Linecaps DE17 by Hot Melt Extrusion. AAPS PharmSciTech. 2016; 17: 99-105. DOI: 10.1208/s12249-015-0374-1
81. Roland B. Tableting of coated pellets. Eur J Pharm Biopharm. 1997; 43: 1-8. DOI: 10.1016/S0939-6411(96)00028-8

82. Takashi Y, Misuzu Y, Hiroshi Y, Masanori Y. Tableting of coated particles II. Influence of particle size of pharmaceutical additives on protection of coating membrane from mechanical damage during compression process. Chem Pharm Bull. 1998; 46: 826-830.

83. Chin WC, Chan LW, Heng PW. A mechanistic investigation on the utilization of lactose as a protective agent for multi-unit pellet systems. Pharm Dev Technol. 2016; 21: 222-230. DOI: 10.3109/10837450.2014.991875

84. Lin X, Chyi CW, Ruan KF, Feng Y, Heng PW. Development of potential novel cushioning agents for the compaction of coated multi-particulates by co-processing micronized lactose with polymers. Eur J Pharm Biopharm. 2011; 79: 406-415. DOI: 10.1016/j.ejpb.2011.03.024

85. Xu M, Heng PW, Liew CV. Formulation and process strategies to minimize coat damage for compaction of coated pellets in a rotary tablet press: A mechanistic view. Int J Pharm. 2016; 499: 29-37. DOI: 10.1016/j.ijpharm.2015.12.068

86. Chen SJ, Zhu JB, Qi XL. [Evaluation with compression equations of compression behavior of pellets with different intragranular pore volumes]. Yao Xue Xue Bao. 2009; 44: 412-416.

87. Vergote GJ, Kiekens F, Vervaet C, Remon JP. Wax beads as cushioning agents during the compression of coated diltiazem pellets. Eur J Pharm Sci. 2002; 17: 145-151. DOI: 10.1016/S0928-0987(02)00164-1

88. David L. Mount, oseph B. Schwartz. Formulation and Compaction of Nonfracturing Deformable Coated Beads. Drug Dev. Ind. Pharm. 1996; 22: 609-621. DOI: 10.3109/03639049609063215

89. Nguyen C, Christensen JM, Ayres JW. Novel mesalamine-loaded beads in tablets for delayed release of drug to the colon. Pharm Dev Technol. 2012; 17 : 73-83. $\quad$ DOI: 10.3109/10837450.2010.516436

90. Qi XL, Zhu JB, Chen SJ. [Preparation of tablets containing enteric-coated diclofenac sodium pellets]. Yao Xue Xue Bao. 2008; 43: 97-101.

91. Cantor SL, Hoag SW, Augsburger LL. Formulation and characterization of a compacted multiparticulate system for modified release of water-soluble drugs--part 1--acetaminophen. Drug Dev Ind Pharm. 2009; 35: 337-351. DOI: 10.1080/03639040802360502

92. Cantor SL, Hoag SW, Augsburger LL. Formulation and characterization of a compacted multiparticulate system for modified release of water-soluble drugs--Part II theophylline and cimetidine. Drug Dev Ind Pharm. 2009; 35: 568-582. DOI: $10.1080 / 03639040802459460$

93. Bendas ER, Christensen JM, Ayres JW. Development and in vitro evaluation of 
mesalamine delayed release pellets and tableted reservoir-type pellets. Drug Dev Ind Pharm. 2010; 36: 393-404. DOI: 10.3109/03639040903213717

94. Li X, Xu de S, Li M, Liu L, Heng P. Preparation of co-spray dried cushioning agent containing stearic acid for protecting pellet coatings when compressed. Drug Dev Ind Pharm. 2016; 42: 788-795. DOI: 10.3109/03639045.2015.1075034. 